\title{
Physical Activity and Nutrition Interventions and Physical Self-Image in Youth
}

\author{
Rebecca Williams ${ }^{1}$, Claudio Nigg ${ }^{1}$, \& Mae Oda ${ }^{2}$ \\ ${ }^{1}$ Department of Public Health Sciences \& Epidemiology, University of Hawaii at Manoa, \\ ${ }^{2}$ Waiakea School Complex
}

\begin{abstract}
The importance of improving physical self-image and its related consequences in youth provided the rationale for this study. Based on the Exercise and Self-Esteem Model, the adapted Health Behavior and Self-Esteem Model provides an explanation of behavior (physical activity and nutrition) leading to selfimage. We found that physical activity and nutrition were related with self-image by gender and grades (4-12) during a school year. Cross-sectional pre- ( $n=263 ; 52.9 \%$ female) and post- ( $n=287 ; 51.5 \%$ female) intervention data revealed that: males generally belonged to more active groups; males were more satisfied with their physical body attributes than their female peers; and that $82 \%$ of the physical activity, nutrition, and self-image study variables remained stable across time. The maintaining of health behaviors mirroring the maintenance of physical self-image lends credence to this aspect of the adapted Health Behavior and Self Esteem Model. More rigorous testing of the full Model is warranted.
\end{abstract}

(c) 2005 Californian Journal of Health Promotion. All rights reserved.

Keywords: physical activity, nutrition, health behavior, youth

Physical self-image is defined as subjective perceptions and attitudes that one has about their physical body attributes (i.e. body shape, weight) and physical fitness attributes (i.e. strength, coordination) (Carron, Hausenblas, \& Estabrooks, 2003). Physical self-image is an important concern for youth. Approximately two-thirds of adolescent girls at any age are dissatisfied with their weight, the proportion increasing with actual weight, and slightly more than half of all girls are dissatisfied with the shape of their bodies, an attitude which is also positively correlated with body weight (Moore, 1993). Girls are most likely to be distressed about the excess size of their thighs, hips, waist and buttocks, and inadequate size of their breasts (Moore, 1993).

Physical self-image is also a concerning topic for males. Approximately one-third of boys are dissatisfied with their body shape, desiring larger upper arms, chest and shoulders (Moore, 1993). Therefore, it is important to promote a healthy sense of physical self-image as it is a component of self-esteem.
The Exercise and Self-Esteem Model posits that exercise leads to self-competence and acceptance which then leads to self-esteem (Sonstroem \& Morgan, 1989; Sonstroem, Harlow, Gemma, \& Osborne, 1991). This model can be conceptualized more generally to include health behavior (physical activity and nutrition) affecting the variables of physical selfacceptance and self-efficacy (see Figure 1). Therefore, the proposed Health Behavior and Self-Esteem Model (HBSEM) provides a possible explanatory mechanism between health behaviors, self-image, self-efficacy and selfesteem.

However, prospective studies document marked declines in physical activity among children aged 9 to 14 years (Barnett, O'Loughlin, \& Paradis, 2002). Furthermore, studies have shown that girls belong to sedentary and low activity groups, while boys frequently belong to more active groups (Mota \& Esculas, 2002; Sunnegardh, Bratteby, \& Sjolin, 1985). In a study of 8-13 year old children, it was found that the younger children of each sex tend to be more 
physically active than the older ones (Sunnegardh, et al, 1985).

Decreased concerns with eating are seen as age increases in boys, while girls tend to have increased concerns about eating with age (Ohzeki, et al, 1993). Furthermore, eating behaviors in girls tend to be less influenced by changes in body weight than in boys (Ohzeki, et al, 1993).

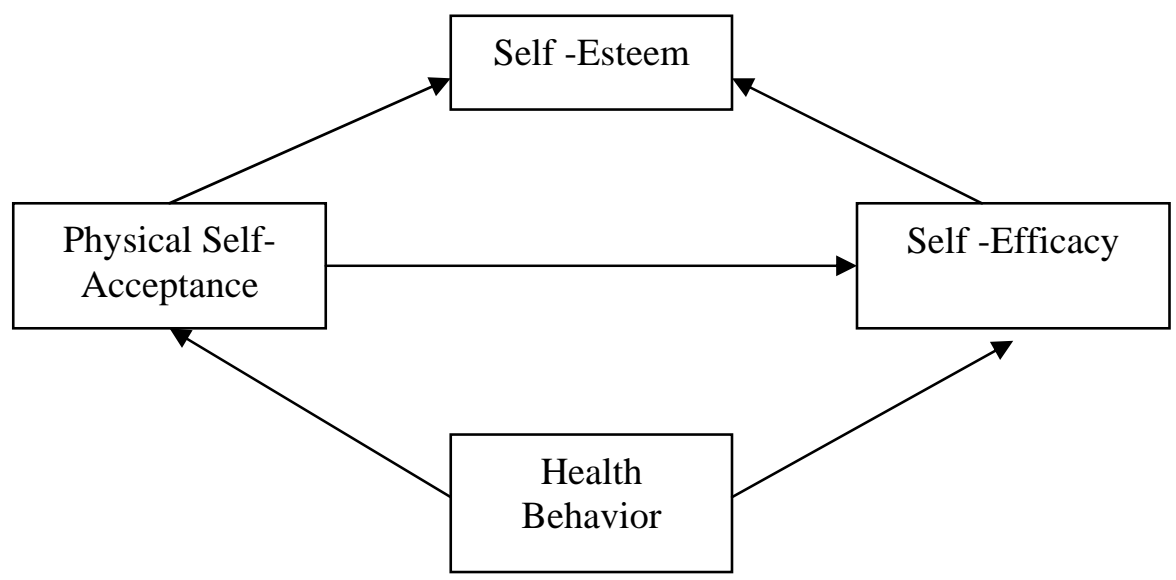

Figure 1

Health Behavior and Self-Esteem Model

That engaging in health behaviors leads to selfefficacy is well accepted in the literature (Bandura, 1997). Although much research has indicated an increase in self-image as a result of physical activity (Fox, 2000), few studies show how nutrition interventions for youth may affect self-image. More studies are required to illustrate if and how the combination of physical activity and nutrition may affect self-image in youth.

Therefore, the purpose of this study was to explore possible relations of physical activity and nutrition interventions on self-image in youth. Specifically, this study investigated if physical activity and nutrition interventions across gender and grade affect self-image, therefore illuminating what gender and age groups self-image issues are prevalent.

\section{Method}

\section{Participants}

This was a multiple cross-sectional study design. A total of 263 student questionnaires at time one and 287 questionnaires at time two were collected, roughly half male and half female (for complete participant details collected at each time point, see Table 1).

\section{Procedures}

Upon approval of the Institutional Review Board, anonymous questionnaires were administered to one class per grade (4-12; to ensure representation across grades) at each school in a Hawaii complex, which consisted of two elementary schools, one intermediate school, and one high school. Classes were selected to participate in the study based on the teacher's willingness to administer the survey at each time point. Questionnaires were distributed to interested teachers by the school complex health promotion coordinator. The coordinator collected cross-sectional data during the fall semester 2002 (time one) and spring semester 2003 (time two).

Interventions promoting physical activity and healthy nutrition were implemented in each school over the course of two semesters. Refer to Appendix A and Appendix B for intervention details. 
Table 1

Study Characteristics

\begin{tabular}{|c|c|c|c|c|c|c|}
\hline Variable & N Time 1 & \% Time 1 & N Time 2 & \% Time 2 & N T1+T2 & \% T1+T2 \\
\hline Participants & 263 & 100 & 287 & 100 & 550 & 100 \\
\hline Gender & & & & & & \\
\hline Male & $123^{*}$ & $46.8^{*}$ & 139 & 48.4 & $262^{*}$ & $47.6^{*}$ \\
\hline Female & $139^{*}$ & $52.9^{*}$ & 148 & 51.6 & $287^{*}$ & $52.2^{*}$ \\
\hline Grade & & & & & & \\
\hline 4 & 48 & 18.3 & 42 & 14.6 & 90 & 16.4 \\
\hline 5 & 48 & 18.3 & 49 & 17.1 & 97 & 17.6 \\
\hline 6 & 28 & 10.6 & 28 & 9.8 & 56 & 10.2 \\
\hline 7 & 22 & 8.4 & 27 & 9.4 & 49 & 8.9 \\
\hline 8 & 21 & 8.0 & 36 & 12.5 & 57 & 10.4 \\
\hline 9 & 25 & 9.5 & 26 & 9.1 & 51 & 9.3 \\
\hline 10 & 19 & 7.2 & 24 & 8.4 & 43 & 7.8 \\
\hline 11 & 11 & 4.2 & 27 & 9.4 & 38 & 6.9 \\
\hline 12 & 41 & 15.6 & 28 & 9.8 & 69 & 12.5 \\
\hline
\end{tabular}

Note. * Sample sizes smaller for some variables because of missing data.

Data representative of a multiple cross-sectional study design.

\section{Measures}

Demographic questions were asked regarding gender, grade level, and school of attendance (elementary, intermediate, or high school).

Physical Activity Assessment. The Godin's Leisure-Time Exercise Questionnaire (GLTEQ), a self-report instrument that assesses the frequency of strenuous, moderate, and mild leisure-time physical activity that is performed during a typical week, was used (Godin, Jobin, Bouillon, 1986). A total exercise index (weekly metabolic equivalents) is calculated by multiplying the frequency of each intensity and summing for a total score using the following formula: $\quad 3 *$ (mild) $+5 *$ (moderate) $+9 *$ (strenuous). The GLTEQ is a psychometrically sound measure of exercise behavior (Godin et al., 1986; Jacobs, Ainsworth, Hartman, Leon, 1993) and has been related to other indices of physical activity in adolescents (Lee, Nigg, DiClemente, Courneya, 2001).

Additionally, the number of hours watching television/playing video games (sedentary behavior) was obtained. One-week test-retest reliabilities of 0.72 were documented (Wallace, Buckworth, Kirby, Sherman, 2000).

Nutrition (Fruit and Vegetable) Assessment. Single item questions inquired about the average number of fruits and the average number of vegetables eaten each day. Validity with a 3-day food record $(\mathrm{r}=.35, \mathrm{p}<.01)$ and reliability $(\mathrm{r}=.53)$ were good in an adolescent sample using similar measures (Prochaska, Sallis, Rupp,Wade, \& Long, 2000).

Physical Self-Image Assessment. Students rated two aspects of their physical self-image: their physical body attributes and physical fitness attributes. These attributes were rated on a scale from one ("I really don't like this and wish I could change it") to five ("I really like this and do not want to change it”).

Measures of physical body attributes were adapted from the literature (Moore, 1993). This measure assessed satisfaction with the following components: waist, body build, height, weight, shoulder width, chest, health, and appetite. 
Measures of physical fitness attributes were derived from the physical self-concept literature (Marsh, et al, 1994). This measure assessed satisfaction with the following components: strength, endurance, coordination, appearance, and flexibility. These physical activity attributes have been validated with Australian adolescents (Marsh et al., 1994), American college students (Nigg, Norman, Rossi, Benisovich, 2001), and are significantly related to components of physical fitness (Marsh \& Redmayne, 1994) and other self-concepts (Marsh et al., 1994).

\section{Analysis}

Statistical analysis was performed using SPSS 11.0 (SPSS Inc.) statistical software. Descriptives of the demographics by time and each physical self-image variable by time and grade were determined. Bivariate correlations determined the degree of association between each study variable for each time period.

The differences between time one and time two for each gender were calculated using time as the independent variable and the study variables as the dependent variables. The difference between genders within each time point was calculated using gender as the independent variables and the study variables as the dependent variables. As this was an exploratory analysis, significance levels were set a priori at 0.05 .

\section{Results}

\section{Correlations}

Appendix C shows correlations between study variables for time one for males and females. Physical body and physical fitness variables correlated with each other, but few were related to physical activity, inactivity, and nutrition behaviors.

Appendix D shows correlations between study variables for time two for each gender. Similar to time one, time two correlations showed that the physical body and physical fitness variables were correlated with each other. Few of these variables, however, were correlated with physical activity, inactivity, and nutrition behaviors.
There was no significant difference in correlations between time periods. In both time periods, physical body and physical fitness variables were mostly related to the variables of fruit consumption per day and vegetable consumption per day.

\section{Grade}

Variable Differences Across Time Per

Appendix E describes the significant differences in the study variables across time for each grade. Of those grades that had a significant score difference for the study variables from time one to time two, all but two had lower scores at time two. Further, there is an obvious pattern of significantly lower scores at time two in satisfaction with shoulder width for males in grades ten, eleven, and twelve.

\section{Grade}

Gender Differences by Time and

Appendix F describes the significant differences in the study variables across for each gender by time and grade. More males than females had a significantly higher score for the study variables by grade. This was especially noticeable in the following study variables: height, weight, shoulder width, health, appetite, strength, endurance, coordination, appearance, and flexibility. No significant patterns were found for differences across time.

\section{Self-Image Attribute Changes}

Overall means showed that males' satisfaction with their self-image was lower at time two compared to time one, except for grades five and nine that were higher. Female overall means showed higher self-image satisfaction in grades four, seven, eight, ten, and twelve at time two versus time one.

At time one, males of all grades except grade nine had higher self-image satisfaction than females. During time two, females had higher self-image than males in grades four, six, eight, ten, and twelve. For details on mean self-image attribute changes across gender and grade, see Figure 2. 


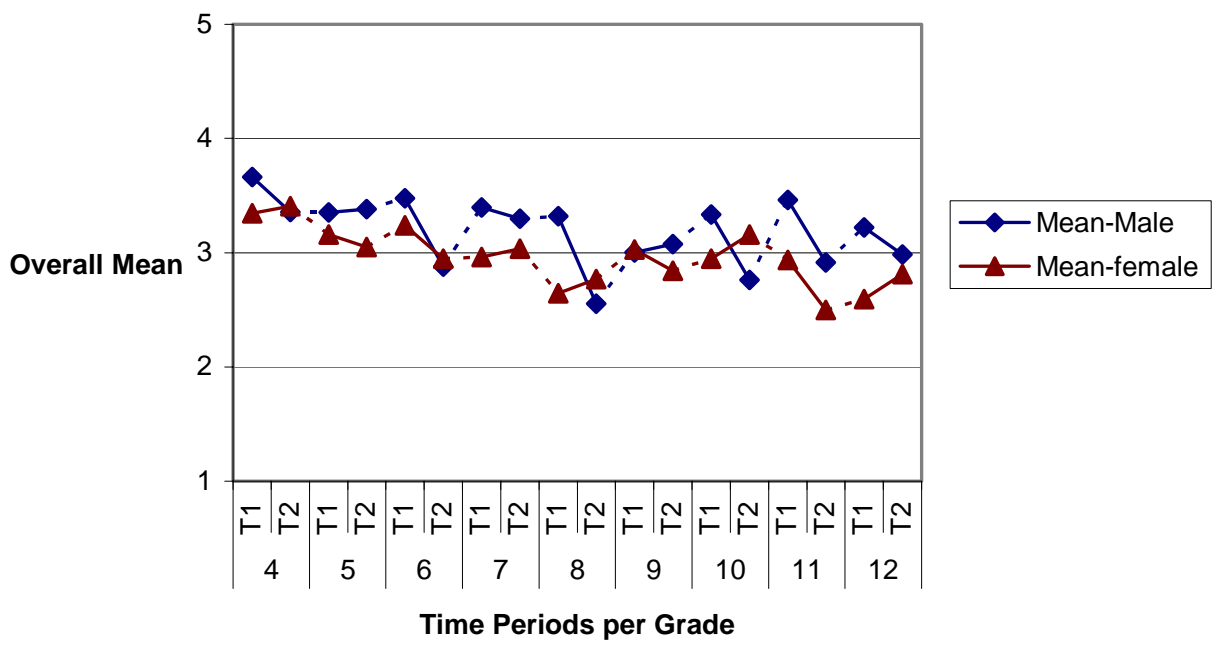

Figure 2

Overall Mean Changes in Self-Image Attributes

\section{Discussion}

This study explored the possible relationships of physical activity and nutrition interventions on self-image in youth. Results showed that physical activity and nutrition was maintained over time, contrary to research that indicates that physical activity and nutrition decrease over time. This is possibly due to our intervention efforts. Furthermore, this study showed that physical self-image was also maintained over time, possibly due to the maintenance of physical activity and nutrition levels.

Our results are consistent with other studies that showed that males generally belong to more active groups than females (Mota \& Esculas 2002; Sunnegardh, et al., 1985). Furthermore, our results show that males are more satisfied with their physical body attributes than their female peers. Our findings are also consistent with the idea that females are more dissatisfied with their body shape than are males (Moore, 1993).

Eighty-two percent of the physical activity, nutrition, and self-image study variables remained stable across time. Of those that did change significantly, a majority decreased from pre-intervention to post-intervention for both males and females.

Correlation of study variables did not change significantly across time. As expected, the physical body and physical fitness variables were correlated with each other. Interestingly, fruit and vegetable consumption per day were the variables that were most associated with physical body and physical fitness attributes. The maintaining of health behaviors mirroring the maintenance of physical self-image lends credence to this aspect of the HBSEM. Further research is required to fully investigate the entire model.

Limitations in this study were the use of a multiple cross-sectional study design that did not allow us to measure change. In addition, there was no control group. Dependence on selfreported measures could have introduced positive response bias. Sample selection procedures may have also introduced selection bias into the study. Furthermore, there were inconsistent interventions over all grade levels. However, the maintenance of physical activity 
levels and nutrition consumption, as well as physical self-image levels, is encouraging.

\section{Conclusions}

This study explored the possible relations of physical activity and nutrition interventions on physical self-image in youth. Physical activity and nutrition levels remained constant across time; contrary to research that indicates that these levels decrease over time. Guided by the Health Behavior and Self-Esteem Model, interventions that promote physical activity and nutrition possibly maintain physical self-image in youth.

Future directions need to examine whether the data holds over time, such as over a summer break and, ideally, over years; use a longitudinal cohort of large representative samples and various locations; and evaluate standardized health behavior interventions to produce a positive impact on self-image in youth.

\section{References}

Bandura, A. (1997). Self-efficacy: The exercise of control. New York: W. H. Freeman.

Barnett, T. A., O'Loughlin, J., \& Paradis, G. (2002). One- and two-year predictors of decline in physical activity among inner-city schoolchildren. American Journal of Preventive Medicine, 23, 121-128.

Carron, A. V., Hausenblas, H. A., \& Estabrooks, P. A. (2003). The psychology of physical activity. New York: The McGraw-Hill Companies, Inc.

Fox, K. R. (2000). The effects of exercise on self-perceptions and self-esteem. In S. J. H. Biddle, K. R. Fox, \& S. H. Boutcher (Eds.), Physical activity and psychological well-being (pp. 88-117). London: Routledge.

Godin, G., Jobin, J., \& Bouillon, J. (1986). Assessment of leisure time exercise behavior by self-report: A concurrent validity study. Canadian Journal of Public Health, 77, 359-362.

Jacobs, D. R. Jr, Ainsworth, B. E., Hartman, T. J., \& Leon, A. S. (1993). A simultaneous evaluation of 10 commonly used physical activity questionnaires. Medicine and Science in Sports and Exercise, 25, 81-91.

Lee, R. E., Nigg, C. R, DiClemente, C. C., \& Courneya, K. S. (2001). Validating motivational readiness for exercise behavior with adolescents. Research Quarterly of Exercise and Sports, 72, 401-410.

Marsh, H. W., \& Redmayne, R. S. (1994). A multidimensional physical self-concept and its relation to multiple components of physical fitness. Journal of Sport \& Exercise Psychology, 16, 43-55.

Marsh, H. W., Richards, G. E., Johnson, S., Roche, L., \& Tremayne, P. (1994). Physical self-description questionnaire: Psychometric properties and a multitrait-multi method analysis of relations to existing instruments. Journal of Sport \& Exercise Psychology, 16, 270-305.

Moore, D. C. (1993). Body image and eating behavior in adolescents. Journal of the American College of Nutrition, 12, 505-510.

Mota, J., \& Esculas, C. (2002). Leisure-time physical activity behavior: structured and unstructured choices according to sex, age, and level of physical activity. International Journal of Behavioral Medicine, 9, 111-121.

Nigg, C. R., Norman, G. J., Rossi, J. S., \& Benisovich, S. V. (2001). Examining the structure of physical self-description using an American University sample. Research Quarterly of Exercise and Sports, 72, 78-83.

Ohzeki, T., Otahara, H., Hanaki, K., Motozumi, H., \& Shiraki, K. (1993). Eating attitudes test in boys and girls aged 6-18 years: decrease in concerns with eating in boys and the increase in girls with their ages. Psychopathology, 26, 117-121.

Prochaska, J. J., Sallis, J. F., Rupp, J., Wade, D., \& Long, B. (2000). Brief self reported measures for assessing fat, fruit and vegetable and calcium intake with adolescents. Annals of Behavioral Medicine, 22, S132.

Sonstroem, R. J., Harlow, L. L., Gemma, L. M., \& Osborne, S. (1991). Test of structural relationships within a proposed exercise and self-esteem model. Journal of Personality Assessment, 56, 348364. 
Sonstroem, R. J. \& Morgan, W. P. (1989). Exercise and self-esteem: Rationale and model. Medicine and Science in Sports and Exercise, 21, 329-337.

Sunnegardh, J., Bratteby, L. E., \& Sjolin, S. (1985). Physical activity and sports involvement in 8- and 13-year-old children in Sweden. Acta Paediatrica Scandinavica, 74, 904-912.

Wallace, L. S., Buckworth, J., Kirby, T. E., \& Sherman, W. M. (2000). Characteristics of exercise behavior among college students: Application of social cognitive theory to predicting stage of change. Preventive Medicine: An International Journal Devoted to Practice \& Theory, 31, 494505.

\section{Acknowledgements}

Supported by the Hawaii State Department of Health Tobacco Settlement Special Fund.

\section{Bioography}

Rebecca Williams is a Master of Public Health recipient from the Social and Behavioral Health Sciences Program at the Department of Public Health Sciences and Epidemiology, John A. Burns School of Medicine, University of Hawaii at Manoa. Claudio Nigg, Ph.D. is Associate Professor and Chair of the Social and Behavioral Health Sciences Program at the Department of Public Health Sciences and Epidemiology, John A. Burns School of Medicine, University of Hawaii at Manoa. Mae Oda is the school health coordinator for the Waiakea School Complex.

Author Information

Rebecca Williams, M.P.H.

Department of Public Health Sciences \& Epidemiology

John A. Burns School of Medicine

University of Hawaii at Manoa

Claudio R. Nigg, Ph.D.

Associate Professor and Chair

Social and Behavioral Health Sciences Program

Department of Public Health Sciences \& Epidemiology

John A. Burns School of Medicine

University of Hawaii at Manoa

1960 East-West Road

Honolulu, HI 96822

Ph.: 808-956-2862

Fax.: 808-956-5818

E-Mail: cnigg@hawaii.edu

Mae Oda

Waiakea School Complex

* corresponding author 


\section{Appendix A \\ School Intervention Programs}

\begin{tabular}{|l|l|}
\hline \multicolumn{1}{|c|}{ Intervention } & \multicolumn{1}{|c|}{ Grades Invited to Participate } \\
\hline Physical Activity (PA) & \multicolumn{1}{|c|}{} \\
\hline Yoga class & Grades 4-8 parents/children/school staff \\
\hline Low impact aerobics & School staff in complex \\
\hline Dance classes. & Grades 4-8 students \\
\hline After school activities to promote PA. & Grades 4-8 students \\
\hline Community fun walks. & Grades 4-8 parents/children/school staff \\
\hline Walking map and stretching tips. & Grades 6-8 students/school staff \\
\hline Use of pedometers for PA motivation. & Staff at intermediate and high schools \\
\hline Nutrition & \\
\hline Demonstrations to bake healthy baked goods. & Grades 4-8 parents/children/school staff \\
\hline $\begin{array}{l}\text { Healthy gardening-learn to plant and grow salad } \\
\text { vegetables and herbs. }\end{array}$ & Grades 4-8 parents/children/school staff \\
\hline Make quick and healthy breakfasts. & Grades 4-8 parents/children/school staff \\
\hline Healthy eats: prepare fruit and vegetable dishes. & Grades 4-8 parents/children/school staff \\
\hline Healthy choices for snacks and food as rewards. & Grades 4-8 parents/children/school staff \\
\hline $\begin{array}{l}\text { Healthier alternatives to soda (e.g. milk and } \\
\text { juice). }\end{array}$ & $\begin{array}{l}\text { Grade 9-12 students/staff; policy Grades K-5 } \\
\text { parents/students, Grade 6-8 students/staff }\end{array}$ \\
\hline $\begin{array}{l}\text { 5-A-Day to better health posters, bulletins, } \\
\text { newsletters. }\end{array}$ & Grades 4-8 parents/children/school staff \\
\hline $\begin{array}{l}\text { "Krazy Kowz" campaign: selling strawberry, } \\
\text { chocolate, and plain 2\% milk. }\end{array}$ & Grades 9-12 students/school staff \\
\hline $\begin{array}{l}\text { Elementary and intermediate schools do not allow } \\
\text { candy and soda to be brought to school. }\end{array}$ & $\begin{array}{l}\text { Grades K-5 parents/children/school staff Grades } \\
\text { 6-8 parents/children/school staff }\end{array}$ \\
\hline Salads at lunch twice a week. & Grades 9-12 students/school staff \\
\hline Other & \\
\hline $\begin{array}{l}\text { Body fat/weight measures for five months. } \\
\text { Health school newsletter }\end{array}$ & Intermediate school staff \\
\hline Drama to teach about nutrition and PA & Grades 4-12 parents/children/school staff \\
\hline $\begin{array}{l}\text { Healthy fair } \\
\text { Promote activities sponsored by community } \\
\text { March of Dimes) }\end{array}$ & Grade 7-8 students \\
\hline 6-8 students/school staff \\
\hline & Grades 4-8 parents/children/school staff \\
\hline
\end{tabular}




\section{Appendix B}

Intervention Purchases (time 1-time 2)

\begin{tabular}{|c|c|c|}
\hline Elementary Schools & Intermediate School & High School \\
\hline 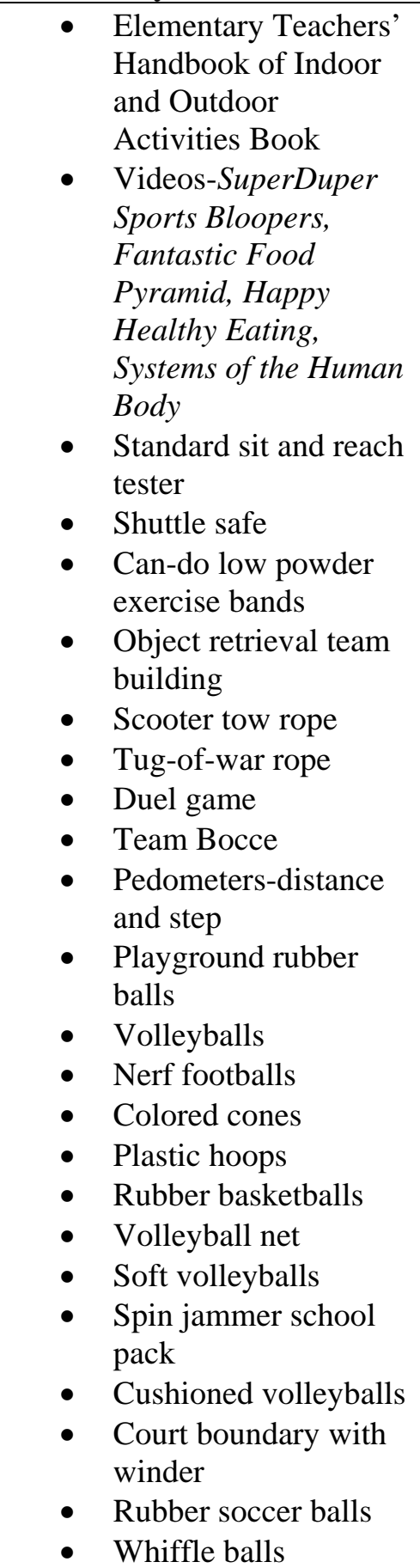 & $\begin{array}{l}\text { - } \text { Texts-Teen Health } \\
\text { - } \text { Course I } \\
\text { - } \text { Back to back system } \\
\text { - } \text { Balls eye back goals } \\
\text { - Inflator/deflator } \\
\text { - } \text { Pedometers } \\
\text { - Rhino skin foam balls } \\
\text { - } \text { Front mounted fixed } \\
\text { - } \text { Basketball net } \\
\text { - } \text { Dyna bands } \\
\text { - Scog belts } \\
\end{array}$ & $\begin{array}{ll}\text { - } & \text { Texts- Glencoe } \\
& \text { Health, A Guide To } \\
& \text { Wellnesss., } 2001 \\
\text { - } & \text { Airman Inflator } \\
\text { - Shape up mats } \\
\text { - Weighted base cones } \\
\text { - } \text { Dyna bands }\end{array}$ \\
\hline
\end{tabular}




\section{Appendix C}

\section{Time One Correlations}

\begin{tabular}{|c|c|c|c|c|c|c|c|c|c|c|c|c|c|c|c|c|c|c|c|c|}
\hline & Gen & ctr & mod activ 1 & mil activ & v/vgam & frt/dy & veg/dy & waist & bd bld & height & weight & shld wdth & chest & health & appet & strength & enduran & coord & appear & flexab \\
\hline stren act & $\mathrm{M}$ & 1 & $.547(* *)$ & $.275(* *)$ & 0.067 & $.183(*)$ & 0.156 & -0.018 & 0.114 & $.216(*)$ & -0.049 & 0.141 & 0.027 & 0.178 & $.195\left(^{*}\right)$ & -0.009 & $9.235(* *)$ & 0.027 & 0.119 & 0.052 \\
\hline & $\mathrm{F}$ & 1 & $.487(* *)$ & $.309(* *)$ & -0.04 & 0.146 . & $.224(* *)$ & 0.096 & 0.144 & 0.11 & $.175\left(^{*}\right)$ & $.201\left(^{*}\right)$ & 0.065 & $.176\left(^{*}\right)$ & 0.156 & 0.134 & $4.246(* *)$ & 0.168 & 0.102 & 0.153 \\
\hline $\begin{array}{l}\text { mod } \\
\text { activ }\end{array}$ & M & & 1 & $.481(* *)$ & -0.062 & 0.063 & 0.148 & $.254(* *)$ & -0.122 & -0.054 & -0.16 & -0.062 & $-.231(*)$ & -0.162 & -0.018 & $-.186(*)$ & -0.001 & -0.008 & -0.08 & -0.131 \\
\hline & $\mathrm{F}$ & & 1 & $.465(* *)$ & 0.028 & $.237(* *)$ & $.287(* *)$ & 0.082 & 0.043 & -0.006 & 0.08 & 0.107 & 0.077 & 0.02 & 0.049 & 0.065 & 0.118 & 0.16 & 0.085 & 0.089 \\
\hline mil activ & $\mathrm{M}$ & & & 1 & 0.078 & -0.009 & 0.112 & -0.084 & -0.162 & -0.065 & -0.04 & -0.09 & -0.115 & -0.116 & 0.16 & -0.134 & 0.055 & 0.005 & -0.021 & -0.077 \\
\hline & $\mathrm{F}$ & & & 1 & 0.16 & 0.079 & $.187(*)$ & -0.027 & -0.018 & -0.095 & 0.075 & -0.023 & -0.005 & -0.076 & 0.037 & -0.118 & -0.056 & 0.038 & -0.111 & 0.105 \\
\hline tv/vgame & eM & & & & 1 & -0.174 & -0.04 & -0.015 & -0.049 & 0.019 & 0.03 & -0.01 & 0.036 & -0.027 & 0.069 & -0.092 & 0.066 & -0.092 & 0.066 & 0.001 \\
\hline & $\mathrm{F}$ & & & & 1 & -0.116 & $-.185(*)$ & -0.141 & $-.179(*)$ & -0.118 & -0.02 & -0.107 & -0.054 & -0.166 & $-.173(*)$ & $-.201(*)$ & -0.141 & -0.109 & $-.210(*)$ & -0.086 \\
\hline frt/dy & M & & & & & & $.529(* *)$ & 0.008 & $.268(* *)$ & -0.051 & 0.064 & 0.116 & $.191\left(^{*}\right)$ & $.258(* *)$ & 0.106 & 0.176 & 0.175 & 0.086 & 0.149 & -0.009 \\
\hline & $\mathrm{F}$ & & & & & 1 . & $.471(* *)$ & $.291(* *)$ & $.188(*)$ & 0.113 & 0.131 & $.216\left(^{*}\right)$ & $.190\left(^{*}\right)$ & 0.133 & $.190\left(^{*}\right)$ & 0.061 & 0.07 & 0.033 & 0.111 & 0.128 \\
\hline veg/dy & M & & & & & & 1 & -0.085 & 0.113 & -0.041 & 0.056 & 0.029 & 0.06 & 0.021 & 0.077 & 0.035 & 0.043 & 0.14 & -0.044 & -0.031 \\
\hline & F & & & & & & 1 & $.217(*)$ & 0.153 & 0.084 & 0.15 & 0.094 & 0.054 & 0.012 & 0.125 & 0.004 & 0.026 & 0.043 & 0.164 & $.176\left(^{*}\right)$ \\
\hline waist & M & & & & & & & & $322(* *)$ & $.236(* *)$ & $.548(* *)$ & $.330(* *)$ & $.430(* *)$ & $.247(* *)$ & 0.169 & $.310(* *)$ & $.264(* *)$ & $.366(* *)$ & $.455(* *)$ & $.255(* *)$ \\
\hline & F & & & & & & & & $.448(* *)$ & $.307(* *)$ & $.575(* *)$ & $.417(* *)$ & $.390(* *)$ & $.261(* *)$ & $.581(* *)$ & $.351(* *)$ & $.289(* *)$ & $.206\left(^{*}\right)$ & $.401(* *)$ & $.447(* *)$ \\
\hline bd bld & M & & & & & & & & & $.226(*)$ & $.364(* *)$ & $.361(* *)$ & $.581(* *)$ & $.322(* *)$ & -0.023 & $.510(* *)$ & $.347(* *)$ & $.205\left(^{*}\right)$ & $.401(* *)$ & $.313(* *)$ \\
\hline & $\mathrm{F}$ & & & & & & & & & $.415(* *)$ & $.524(* *)$ & $.559(* *)$ & $.400(* *)$ & $.544(* *)$ & $.482(* *)$ & $.467(* *)$ & $.528(* *)$ & $.326(* *)$ & $.384(* *)$ & $.391(* *)$ \\
\hline height & M & & & & & & & & & & $.195(*)$ & 0.174 & $.234(* *)$ & $.221\left(^{*}\right)$ & 0.078 & $.353(* *)$ & $.280(* *)$ & 0.171 & 0.033 & $.288(* *)$ \\
\hline & $\mathrm{F}$ & & & & & & & & & & $.320(* *)$ & $.348(* *)$ & $.391(* *)$ & $.362(* *)$ & $.414(* *)$ & $.410(* *)$ & $.364(* *)$ & $.272(* *)$ & 0.166 & $.330(* *)$ \\
\hline weight & M & & & & & & & & & & 1 & 0.16 & $.443(* *)$ & $.264(* *)$ & $.188\left(^{*}\right)$ & $.216(*)$ & $.361(* *)$ & $.330(* *)$ & $.317(* *)$ & $.261(* *)$ \\
\hline & $\mathrm{F}$ & & & & & & & & & & 1 & $.348(* *)$ & $.369(* *)$ & $.410(* *)$ & $.508(* *)$ & $.433(* *)$ & $.405(* *)$ & $.217(*)$ & $.342(* *)$ & $.391(* *)$ \\
\hline $\begin{array}{l}\text { shld } \\
\text { wdth }\end{array}$ & M & & & & & & & & & & & & $.423(* *)$ & 0.171 & -0.01 & $.239(* *)$ & $.230(*)$ & $.268(* *)$ & $.244(* *)$ & $.293(* *)$ \\
\hline & $\mathrm{F}$ & & & & & & & & & & & & $.501(* *)$ & $.401(* *)$ & $.315(* *)$ & $.449(* *)$ & $.413(* *)$ & 0.162 & $.290(* *)$ & $.191(*)$ \\
\hline chest & M & & & & & & & & & & & & & $.299(* *)$ & $.220(*)$ & $.305(* *)$ & $.211(*)$ & $.295(* *)$ & $.527(* *)$ & $.361(* *)$ \\
\hline & $\mathrm{F}$ & & & & & & & & & & & & & $.394(* *)$ & $.475(* *)$ & $.352(* *)$ & $.279(* *)$ & 0.159 & $.350(* *)$ & $.287(* *)$ \\
\hline health & M & & & & & & & & & & & & & & $.354(* *)$ & $.255(* *)$ & $.419(* *)$ & $.225(*)$ & $.344(* *)$ & $.333(* *)$ \\
\hline & $\mathrm{F}$ & & & & & & & & & & & & & & $.490(* *)$ & $.535(* *)$ & $.525(* *)$ & $.424(* *)$ & $.418(* *)$ & $.386(* *)$ \\
\hline appet & M & & & & & & & & & & & & & & & 0.023 & $.190(*)$ & 0.173 & $.302(* *)$ & 0.089 \\
\hline & $\mathrm{F}$ & & & & & & & & & & & & & & & $.350(* *)$ & $.250(* *)$ & $.297(* *)$ & $.434(* *)$ & $.345(* *)$ \\
\hline strength & M & & & & & & & & & & & & & & & & $1.419(* *)$ & $.292(* *)$ & $.229(*)$ & $.271(* *)$ \\
\hline
\end{tabular}



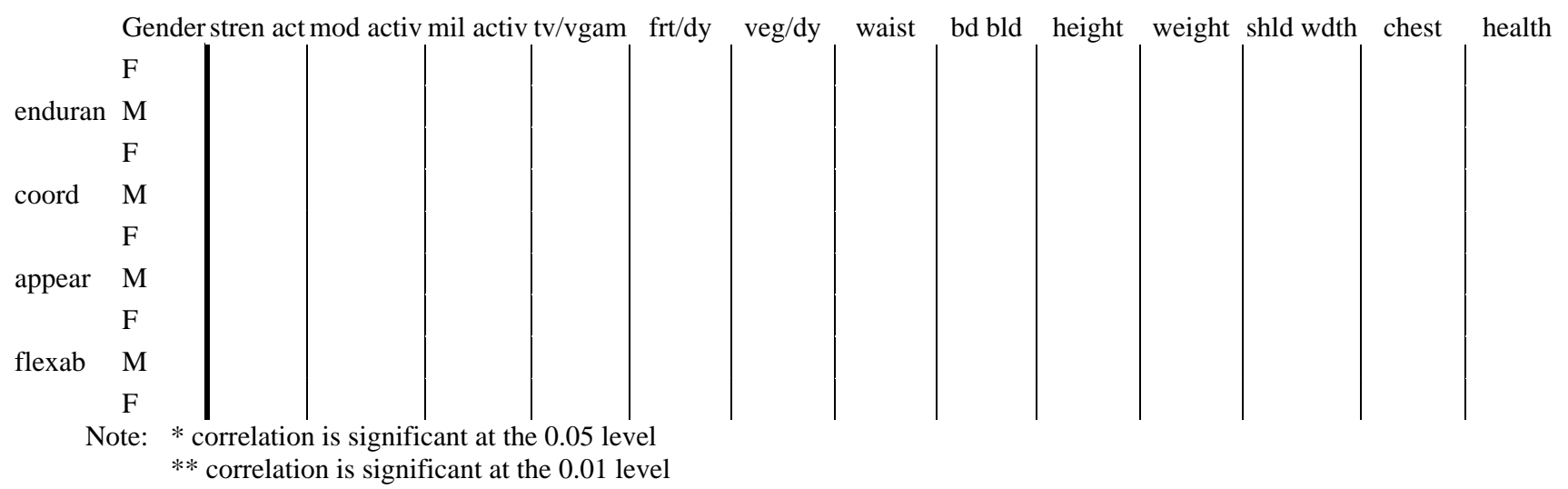

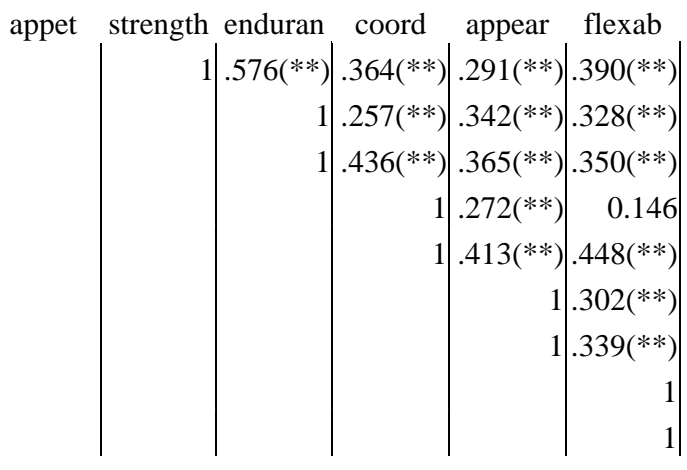




\section{Appendix D}

\section{Time Two Correlations}

Stren Mod Mil tv

Shld

\begin{tabular}{|c|c|c|c|c|c|c|c|c|c|c|c|c|c|c|c|c|c|c|c|c|}
\hline & Gender & act & activ & activ & vgam & frt/dy & veg/dy & waist & bd bld & height & weight & wdth & chest & health & appet & strength & enduran & coord & appear & flexab \\
\hline \multirow[t]{2}{*}{ stren act } & M & 1 & $.451(* *)$ & $.197(*)$ & -.077 & .127 & .104 & -.053 & .080 & .076 & .086 & .076 & -.025 & .010 & .018 & .111 & .039 & -.089 & -.073 & -.019 \\
\hline & F & 1 & $.547(* *)$ & .091 & -.008 & $.295(* *)$ & .131 & .079 & .066 & -.089 & .006 & -.029 & .088 & .135 & .057 & -.017 & .076 & .039 & .069 & $.195(*)$ \\
\hline \multirow[t]{2}{*}{ mod activ } & M & & 1 & $.430(* *)$ & .089 & .074 & .086 & -.070 & -.101 & -.111 & -.039 & .014 & -.025 & .101 & .028 & -.074 & -.012 & -.029 & -.085 & -.081 \\
\hline & F & & 1 & $.307(* *)$ & -.086 & $.214\left({ }^{* *}\right)$ & $.199(*)$ & .019 & .113 & .012 & .103 & -.035 & -.035 & .065 & .039 & .108 & .061 & -.042 & .056 & .064 \\
\hline \multirow[t]{2}{*}{ mil activ } & M & & & 1 & .074 & -.014 & -.035 & -.005 & .042 & -.037 & .038 & -.004 & .004 & .002 & .053 & -.047 & -.095 & -.053 & .014 & -.115 \\
\hline & $\mathrm{F}$ & & & 1 & -.092 & .002 & .162 & -.014 & .017 & .137 & .103 & .119 & .035 & .056 & .162 & .127 & .021 & .026 & .086 & .099 \\
\hline \multirow[t]{2}{*}{ tv/vgame } & M & & & & 1 & .040 & .022 & -.102 & .009 & .020 & -.145 & .107 & .034 & .066 & .057 & -.044 & .087 & .082 & -.104 & .045 \\
\hline & $\mathrm{F}$ & & & & 1 & .009 & .065 & -.061 & -.033 & $-.070(*)$ & -.041 & -.001 & .010 & .092 & .021 & .058 & .046 & .099 & .004 & -.054 \\
\hline \multirow[t]{2}{*}{ frt/dy } & M & & & & & 1 & $.605(* *)$ & .107 & .150 & -.057 & .068 & .079 & .015 & .108 & .156 & .163 & $.236(* *)$ & $.242(* *)$ & .113 & 139 \\
\hline & $\mathrm{F}$ & & & & & 1 & $.530(* *)$ & .061 & .023 & -.056 & .016 & .019 & -.005 & $.252(*)$ & $.183(*)$ & .063 & $.240(* *)$ & .103 & .132 & .082 \\
\hline \multirow[t]{2}{*}{ veg/dy } & M & & & & & & 1 & -.207 & .008 & -.164 & .048 & -.068 & -.038 & .094 & .113 & .074 & .084 & $.214(*)$ & .072 & .136 \\
\hline & F & & & & & & 1 & .061 & -.066 & -.071 & .033 & -.080 & .026 & $.197\left(^{*}\right)$ & $.198\left(^{*}\right)$ & .009 & .100 & .002 & .040 & .039 \\
\hline \multirow[t]{2}{*}{ waist } & M & & & & & & & 1 & $.565(* *)$ & $.271(* *)$ & $.603(* *)$ & $.331(* *)$ & $.335(* *)$ & $.377(* *)$ & $.510(* *)$ & $.407\left(^{* *}\right)$ & $.433(* *)$ & $.263(* *)$ & $.522(* *)$ & $.374(* *)$ \\
\hline & $\mathrm{F}$ & & & & & & & 1 & $.436(* *)$ & .111 & $.527(* *)$ & $.326\left(^{*}\right)$ & $.346(* *)$ & $.312\left(^{*}\right)$ & $.350(* *)$ & $.211\left(^{*}\right)$ & $.348(* *)$ & $.165\left(^{*}\right)$ & $.432(* *)$ & $.348(* *)$ \\
\hline \multirow[t]{2}{*}{ bd bld } & M & & & & & & & & 1 & $.299(* *)$ & $.566(* *)$ & $.489(* *)$ & $.548(* *)$ & $.235(* *)$ & $.303(* *)$ & $.397\left(^{* *}\right)$ & $.516(* *)$ & $.306(* *)$ & $.582(* *)$ & $.280(* *)$ \\
\hline & F & & & & & & & & 1 & $.193(*)$ & $.450(* *)$ & $.400\left(^{*}\right)$ & $.378(* *)$ & $.277(* *)$ & $.345(* *)$ & $.349(* *)$ & $.369(* *)$ & $.232\left(^{*}\right)$ & $.361(* *)$ & .147 \\
\hline \multirow[t]{2}{*}{ height } & M & & & & & & & & & 1 & $.256(* *)$ & $.386(* *)$ & .166 & $.204(*)$ & $.178(*)$ & $.316(* *)$ & $.277(* *)$ & .007 & .124 & $212\left(^{*}\right)$ \\
\hline & $\mathrm{F}$ & & & & & & & & & 1 & $.268(* *)$ & $.231\left(^{*}\right)$ & $.209\left(^{*}\right)$ & .053 & $.213(*)$ & $.261(* *)$ & .145 & .093 & .091 & .086 \\
\hline \multirow[t]{2}{*}{ weight } & M & & & & & & & & & & 1 & $.331(* *)$ & $.401(* *)$ & $.409(* *)$ & $.394(* *)$ & $.301(* *)$ & $.409\left(^{* *}\right)$ & $.324(* *)$ & $.480(* *)$ & $.399(* *)$ \\
\hline & F & & & & & & & & & & 1 & $.360\left(^{*}\right)$ & $.274(* *)$ & $.359\left(^{*}\right)$ & $.492(* *)$ & $.218(* *)$ & $.311(* *)$ & .147 & $.404(* *)$ & $.187\left(^{*}\right)$ \\
\hline \multirow[t]{2}{*}{ shld wdth } & M & & & & & & & & & & & 1 & $.550(* *)$ & $.218(*)$ & $.290(* *)$ & $.309(* *)$ & $.377(* *)$ & .150 & $.321(* *)$ & $.265(* *)$ \\
\hline & F & & & & & & & & & & & 1 & $.512(* *)$ & $.308(*)$ & $.410(* *)$ & $.393(* *)$ & $.297(* *)$ & $.285(*)$ & $.325(* *)$ & .133 \\
\hline \multirow[t]{2}{*}{ chest } & $\mathrm{M}$ & & & & & & & & & & & & 1 & $.183(*)$ & $387(* *)$ & $\left..450{ }^{* *}\right)$ & $.438(* *)$ & $.320(* *)$ & $.525(* *)$ & $.393(* *)$ \\
\hline & F & & & & & & & & & & & & 1 & $.266(*)$ & $.393(* *)$ & $.355(* *)$ & $.327(* *)$ & $.228\left(^{*}\right)$ & $.221(* *)$ & $.182\left(^{*}\right)$ \\
\hline \multirow[t]{2}{*}{ health } & $\mathrm{M}$ & & & & & & & & & & & & & 1 & $.463(* *)$ & $.269(* *)$ & $.369(* *)$ & $.288(* *)$ & $.233(* *)$ & $.185(*)$ \\
\hline & $\mathrm{F}$ & & & & & & & & & & & & & 1 & $.458(* *)$ & $.290\left(^{* *}\right)$ & $.433(* *)$ & $.269(*)$ & $.358(* *)$ & $.339(* *)$ \\
\hline \multirow[t]{2}{*}{ appet } & $\mathrm{M}$ & & & & & & & & & & & & & & 1 & $.337\left(^{* *}\right)$ & $.364(* *)$ & $.379(* *)$ & $.383(* *)$ & $.216\left(^{*}\right)$ \\
\hline & $\mathrm{F}$ & & & & & & & & & & & & & & 1 & $.298(* *)$ & $.410(*)$ & $.216\left(^{*}\right)$ & $.375(* *)$ & $.243(* *)$ \\
\hline \multirow[t]{2}{*}{ strength } & M & & & & & & & & & & & & & & & 1 & $.429(* *)$ & $.345(* *)$ & $.463\left(^{* *}\right)$ & $.446(* *)$ \\
\hline & $\mathrm{F}$ & & & & & & & & & & & & & & & 1 & $.395(* *)$ & $.226(*)$ & $.214\left(^{*}\right)$ & $.209\left(^{*}\right)$ \\
\hline
\end{tabular}



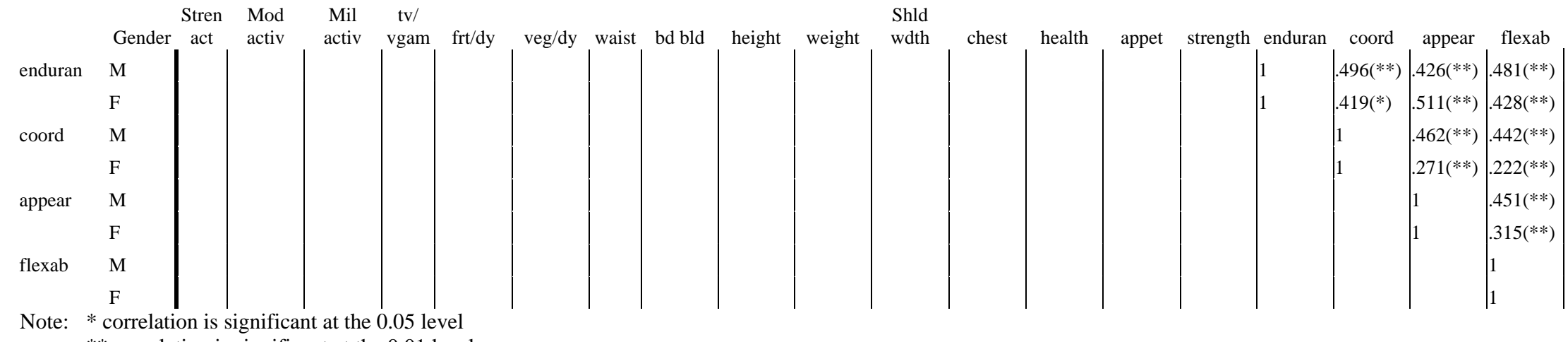

** correlation is significant at the 0.01 level 


\section{Appendix E}

\section{Significant variable differences across time by grade}

\begin{tabular}{|c|c|c|c|c|c|c|c|c|c|c|c|c|c|c|c|c|c|c|c|}
\hline & Variables: & & & & & & & & & & & & & & & & & & \\
\hline Grade & stren act & mod activ & mil actiy & twryamm & fitidy & veridy & waist & bd bld & height & weight & shll woth & chest & heatth & appet & strength & enduran & coord & anpear & flexat \\
\hline $4 M$ & & & & & & & $V$ & & & & & & $V$ & & & & $V$ & & \\
\hline$F$ & & & & & $\downarrow$ & & & & & & & & & & & & & & \\
\hline $5 M$ & & $v$ & & & & & & & & & & & & & & & & & \\
\hline$F$ & & & & & & & & & & & & & $v$ & & & & & & \\
\hline $6 M$ & $V$ & & & & & & & $v$ & & & & & & & & $V$ & & & \\
\hline$F$ & & & & & & & & & $v$ & & & & & & & & & & \\
\hline $7 \mathrm{M}$ & & & & & & & & & & & & & & & & & & & \\
\hline$F$ & $V$ & & & & & & & & & & & & & & & & & & \\
\hline $8 M$ & & & & & & & $V$ & $V$ & & & & $V$ & & & $V$ & $V$ & & $V$ & \\
\hline $\mathrm{F}$ & & & & & & & & & & & & & & & & & & & \\
\hline $9 M$ & & & & & & & & & & & & & & $v$ & & & & & \\
\hline$F$ & & & 1 & & & & & & & & & & & & & & & & \\
\hline $10 \mathrm{M}$ & & & $V$ & & & & & $v$ & $V$ & & $V$ & & & & & & & & \\
\hline$F$ & & & & & 1 & & & & & & & & & & & & & & \\
\hline $11 \mathrm{M}$ & & & & & & & $V$ & & & & $v$ & & & & & & & $V$ & \\
\hline $\mathrm{F}$ & & & & & & & & & & & 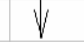 & & & & & & & & \\
\hline $12 \mathrm{M}$ & & & & & & & & & & & v & & & & & & $V$ & & \\
\hline$F$ & & & & & & & & & & & & & & & & & & & \\
\hline & & & & & & & & & & & & & & & & & & & \\
\hline$v$ & significant & |y lower sco & re in time & two comp & areed to tir & & & & & & & & & & & & & & \\
\hline & & & & & & & & & & & & & & & & & & & \\
\hline 1 & significant & ly higher sc & ore in time & et two comp & pared to to & & & & & & & & & & & & & & \\
\hline
\end{tabular}


R. Williams et al. / Californian Journal of Health Promotion 2005, Volume 3, Issue 4, 119-133

\section{Appendix F}

\section{Significant gender differences by time and grade}

\begin{tabular}{|c|c|c|c|c|c|c|c|c|c|c|c|c|c|c|c|c|c|c|c|}
\hline & & Variables & & & & & & & & & & & & & & & & & \\
\hline Grade & Time & stren act & $\bmod$ activ & mil activ & twigam & fitidy & vegidy & waist & bobld & height & weight & shld woth chest & health & appet & strength & enduran & coord & appear & flexab \\
\hline 4 & & 1 & & & & & & & & & & & & & & & M & & \\
\hline & & 2 & & & & & & & & M & & & & & & & & & \\
\hline 5 & & 1 & & & & & & & & M & M & & & & & & & & \\
\hline & & 2 & $\mathrm{~F}$ & & & & & & & & & & M & & M & & & & \\
\hline 6 & & 1 & & & & & & & & & & & & & M & & & & \\
\hline & & 2 & & & & & & & & & & & & & & & & & \\
\hline 7 & & 1 & & & & & & & & & & & & & & & & & \\
\hline & & $2 M$ & & & & & & & M & & & & & & & & & & \\
\hline 8 & & 1 & & & & & & & & & M & M & & & & M & & M & \\
\hline & & 2 & & & & & & & & & & & & & & & & & \\
\hline 9 & & 1 & & & & & & & & & & & & & & & & & \\
\hline & & 2 & & $F$ & & $F$ & & & & & & & & & & & & & \\
\hline 10 & & $1 \mathrm{M}$ & & & & & & & & & & & & & & & M & & \\
\hline & & 2 & & $F$ & & & & & $F$ & $F$ & & & & & & & & & \\
\hline 11 & & 1 & & & & $F$ & & & & & & M & & & & & & & \\
\hline & & 2 & M & M & & & & & & & & & & & & & & & \\
\hline 12 & & $1 \mathrm{M}$ & M & M & & & & & & & M & M & M & & & & M & & \\
\hline & & 2 & & & & & & & & & & & M & & & & & & \\
\hline & & & & & & & & & & & & & & & & & & & \\
\hline & M & Males had & a significa & ntlly higher & score com & pared to 1 & males & & & & & & & & & & & & \\
\hline & $F$ & Females he & lad a signifi & cantly high & her score ce & ompared t & & & & & & & & & & & & & \\
\hline
\end{tabular}

